\title{
Política de dividendos e reputação nas empresas mais responsáveis e com melhor
} governança corporativa*

Dividend and reputation policy in companies that are more responsible and with better corporate governance Política de dividendos y reputación en las empresas más responsables y con mejor gobernanza corporativa

Emanoel Mamede Sousa da Silva ${ }^{a}$

DOI: https://doi.org/10.11144/Javeriana.cc18-46.pdre

Universidade Federal do Ceará, Brasil

emanoel.mamede@gmail.com

ORCID: http://orcid.org/0000-0003-1282-3365

Alessandra Carvalho de Vasconcelos

Universidade Federal do Ceará, Brasil

ORCID: http://orcid.org/0000-0002-6480-5620

Recepção: 03 Janeiro 2017

Aprovação: 14 Fevereiro 2017

Publicado: 15 Dezembro 2017

Paulo Henrique Nobre Parente

Instituto Federal de Educação, Ciência e Tecnologia do

Ceará, Brasil

ORCID: http://orcid.org/0000-0002-4616-7370

Márcia Martins Mendes De Luca

Universidade Federal do Ceará, Brasil

ORCID: http://orcid.org/0000-0002-9995-5637

\section{Resumo:}

O presente estudo investiga a correlação entre a política de dividendos e a reputação das empresas brasileiras listadas no ranking Merco 2014 das empresas mais responsáveis e com melhor governança corporativa. Os dados foram coletados nas demonstrações financeiras e nos formulários de referência de 39 empresas listadas na BM\&FBovespa, do ano 2013. Estes foram analisados para testar as hipóteses de que a política de dividendos -interpretada como um sinal de rentabilidade e redução da assimetria informacional- está correlacionada com a reputação corporativa. Os resultados foram submetidos à análise de homogeneidade, correspondência e correlação. Estes mostraram que (a) as empresas distribuem dividendos principalmente sob a forma de juros sobre capital próprio, (b) empresas familiares tendem a ter uma fraca política de dividendos e baixa reputação corporativa e (c) a política de dividendos está positivamente associada com a reputação corporativa. Assim, à luz da teoria da sinalização, pode-se concluir que a política de dividendos foi positivamente associada à reputação corporativa nas empresas incluídas na amostra.

Códigos JEL: L14, M41

Palavras-chave: Conteúdo informacional, teoria da sinalização, reputação corporativa, política de dividendos.

\section{Abstract:}

In this study, we researched the existent correlation between dividend policy and reputation in firms listed on the 2014 Merco ranking of the most responsible companies with the best corporate governance. We collected information from financial reports and reference forms issued by 39 firms traded on BM\&FBovespa, for year 2013. We analyzed it to test the hypothesis that corporate dividend policy -interpreted as a sign of profitability and reduction of informational asymmetry- is correlated with corporate reputation. We performed homogeneity, correspondence and correlation analysis to the data. Our findings showed that (a) firms distributed dividends mostly in the form of interest on equity, (b) family-owned firms tended to have poor dividend policy and low corporate reputation and (c) the dividend policy was positively associated with corporate reputation. Thus, in light of the signaling theory, we may conclude that dividend policy was positively associated with corporate reputation in the sampled firms.

Keywords: Information content, signaling theory, corporate reputation, dividend policy.

\section{Autor notes}

a Autor de correspondência. Email: emanoel.mamede@gmail.com 


\section{Resumen:}

El presente estudio indaga la correlación entre la política de dividendos y la reputación de las empresas brasileñas enlistadas en el ranking Merco 2014 de las empresas más responsables y con mejor gobernanza corporativa. Los datos fueron recolectados en los estados financieros y en los formularios de referencia de 39 empresas enlistadas en la BM\&FBovespa del año 2013. Estos fueron analizados para probar las hipótesis de que la política de dividendos -interpretada como una señal de rentabilidad y reducción de la asimetría informacional- está correlacionada con la reputación corporativa. Los resultados fueron sometidos al análisis de homogeneidad, correspondencia y correlación. Ellos mostraron que (a) las empresas distribuyen dividendos principalmente bajo la forma de intereses sobre capital propio, (b) las empresas familiares tienden a tener una política débil de dividendos y baja reputación corporativa y (c) la política de dividendos está positivamente asociada con la reputación corporativa. Así, a la luz de la teoría de la señalización, se puede concluir que la política de dividendos fue positivamente asociada a la reputación corporativa en las empresas incluidas en la muestra.

Palabras clave: Contenido informacional, teoría de la señalización, reputación corporativa, política de dividendos.

\section{Introdução}

Os mercados imperfeitos são caracterizados pela presença de assimetria informacional, em que os gestores detêm informações privilegiadas sobre a empresa. Em especial quando comparados com os acionistas, haja vista que estes, em geral, acessam apenas informações públicas, enquanto aqueles estão inseridos no contexto operacional da companhia (Moreiras, Tambosi Filho e Garcia, 2012).

Nesse contexto, a governança corporativa surge com o objetivo de reduzir essa assimetria informacional. Esta, através de um conjunto de mecanismos de monitoramento da gestão e do desempenho da firma (Shleifer e Vishny, 1997), visa alinhar os interesses gerados pelos conflitos de agência entre gestores e proprietários (Jensen e Meckling, 1976). De forma equiparada à governança corporativa, a política de dividendos também pode ser capaz de reduzir a assimetria informacional (Novis Neto e Saito, 2003).

A política de dividendos da empresa, deliberada pelo conselho de administração, está relacionada com as decisões de investimento e financiamento já que o pagamento de dividendos torna inexequível o reinvestimento em novos projetos (Assaf Neto, Ambrozini e Lima, 2007). Estudos empíricos sobre política de dividendos têm dado diferentes enfoques ao assunto: hipótese de sinalização, hipótese de agenciamento, hipótese de preferência tributária e efeito clientela (Loss e Sarlo Neto, 2003). Na perspectiva da hipótese de sinalização, a política de distribuição de dividendos é percebida pelo mercado como sinal sobre a prospecção de desempenho da empresa.

Ao adotar determinada política de dividendos, a empresa emite sinais que, em um ambiente de assimetria informacional, podem ser considerados mecanismos sujeitos à discricionariedade dos stakeholders (Spence, 1973). Especificamente, quando a distribuição de dividendos é majorada, espera-se que o mercado reaja positivamente frente à decisão da empresa. Por outro lado, quando reduzida, o mercado recebe a informação negativa quanto às expectativas futuras da firma (Loss e Sarlo Neto, 2003). Com isso, as empresas são incentivadas a apresentar estratégias de distribuição estáveis, haja vista que esse sinal transmite para os stakeholders a confiança da gestão quanto à situação econômico-financeira da firma (Salsa, 2010).

Loss e Sarlo Neto (2003) defendem que as alterações introduzidas na política de dividendos tendem a influenciar o valor das ações. Zagonel (2013), por sua vez, aponta que a política de dividendos tem implicações distintas na empresa, inclusive para sua reputação. No mesmo sentido, La Porta, Lopez-de-Silanez, Shleifer e Vishny (2000) destacam que o pagamento de dividendos constitui uma das formas da empresa de estabelecer sua reputação, já que reduz a possibilidade dos recursos dos investidores serem expropriados.

A reputação corporativa representa uma avaliação geral dos stakeholders no longo prazo, fundada nas experiências dos principais envolvidos, bem como em outras informações quaisquer sobre as ações das empresas (Gotsi e Wilson, 2001). Pode-se afirmar, então, que a reputação está atrelada às percepções que os principais stakeholders têm sobre a firma, e que a distribuição de dividendos é uma das ações que podem interferir e afetar as percepções dos stakeholders. 
Ao considerar a existência de assimetria informacional, a teoria da sinalização suporta o argumento de que a política de dividendos sinaliza para os stakeholders a sua rentabilidade, bem como as perspectivas futuras da empresa (Fairchild, 2010; Loss e Sarlo Neto, 2003; Pietro Neto, Decourt e Galli, 2011) e, assim, contribui para a sua reputação (Gillet, Lapointe e Raimbourg, 2008).

Diante do exposto, propõe-se a seguinte questão: Qual é a associação entre a política de dividendos e a reputação corporativa nas empresas mais responsáveis e com melhor governança corporativa? Para tanto, o estudo tem como objetivo geral investigar a associação entre política de dividendos e reputação corporativa nas empresas participantes do ranking Merco 2014 "As mais responsáveis e com melhor governança corporativa".

O presente estudo diferencia-se dos demais por realizar uma análise da relação entre a política de dividendos e a reputação corporativa, em um mercado emergente, sob a perspectiva da teoria da sinalização. Embora outros estudos tenham sido desenvolvidos, não foram identificadas investigações que utilizassem uma medida de reputação decorrente de diferentes categorias e com ênfase nas boas práticas de governança corporativa. Cabe destacar ainda que a investigação teórico-empírica realizada compreende, diferentemente das pesquisas levantadas, as empresas participantes de um ranking com a escalação das empresas consideradas mais responsáveis e com melhor governança corporativa que atuam no Brasil, sendo este uma proxy para a reputação corporativa.

A análise do relacionamento entre política de dividendos e reputação assume importância, ao considerar que o pagamento de dividendos é uma forma de estabelecer a reputação da empresa, na medida em que reduz a possibilidade de expropriação dos seus acionistas (La Porta et al., 2000) e emite sinais positivos para o mercado (Fonteles, Peixoto Júnior, Vasconcelos e De Luca, 2012). Diante do exposto, conhecer como se relaciona a política de dividendos e a reputação corporativa pode explicar o comportamento do mercado acionário, isto permite a decisão de gerenciar a política de distribuição de dividendos, o que reforça a justificativa deste estudo. Adicionalmente, investidores podem também subsidiar suas decisões a partir dos construtos de reputação e dividendos, o que permite uma melhor alocação dos seus recursos.

\section{Fundamentação teórica}

O dividendo representa a parte do lucro distribuído com os acionistas, ou seja, o dividendo é uma forma de remunerar ao acionista pelo capital investido (Assaf Neto et al., 2007). Segundo Ross, Westerfield e Jaffe (2013), os dividendos podem ser pagos sob diferentes formas, como por exemplo, em dinheiro, em ações e por meio da recompra de ações. Em mercados emergentes, como o Brasil, a distribuição de lucros compreende uma prática que pode também minimizar a assimetria informacional entre gestores e proprietários e entre acionistas majoritários e minoritários (Dami, Rogers e Ribeiro, 2007).

No Brasil, figuram-se ainda os juros sobre capital próprio (JSCP), criados pela Lei $n^{\circ}$ 9249/1995, como uma forma de evitar o aumento da carga tributária das empresas após a extinção da correção monetária dos demonstrativos contábeis. Ressalte-se que os JSCP também são considerados uma forma de distribuição de dividendos, haja vista que seu montante pode ser deduzido do valor total dos dividendos obrigatórios (Lei 9249, 1995).

A decisão sobre a forma e o volume da distribuição de lucro com os acionistas pode ser entendida como consequência das decisões de investimento e financiamento. Nesse sentido, o pagamento de dividendos será efetuado quando seu volume se mostrar economicamente atraente (Assaf Neto et al., 2007).

Ao levar em conta o ambiente de assimetria de informações, os dividendos são vistos como um mecanismo de redução da incerteza e do risco associados aos seus fluxos de caixa, pois detêm conteúdo informacional (Almeida, Tavares e Pereira, 2014). Além disso, um incremento de dividendos é um sinal para o mercado de que a empresa tem boas perspectivas, o que eleva o preço de suas ações. $\mathrm{O}$ aumento no preço das ações, 
após a sinalização do dividendo é chamado de efeito do conteúdo informacional do dividendo (Ross et al., 2013). Para González (1998), as empresas anunciam mudanças em sua política de dividendos, ao transmitir informações para o mercado.

A redução na política de dividendos pode implicar um sinal negativo, haja vista que o mercado pode compreender, a longo prazo, que a empresa não apresentará níveis de lucratividade desejáveis, o que implica uma redução no seu valor (Gonzáles, 1998). Nesse contexto, emerge a teoria da sinalização (Spence, 1973) que afirma que, em um ambiente de assimetria informacional, os sinais são mecanismos sujeitos à discricionariedade dos gestores capazes de alterar as crenças e transmitir informações. Por sua vez, a teoria da sinalização procura reduzir os conflitos provenientes da assimetria informacional entre a empresa e os stakeholders.

Diante da sua importância, pesquisas recentes investigaram a política de dividendos a partir da teoria da sinalização. Fairchild, Guney e Thanatawee (2014) analisaram a correlação entre a força do poder dos investidores e a política de dividendos em empresas tailandesas. Os autores constataram que o aumento do poder dos investidores resulta em política de distribuição de dividendos elevada.

À luz da teoria da sinalização, os resultados do estudo de Loss e Sarlo Neto (2003) indicaram que os gestores acreditam que os dividendos sustentam sinais sobre o futuro da organização e os dividendos tendem a ser utilizados como redutores de problemas relacionados com conflitos de agência. Pietro Neto, Decourt e Galli (2011) testaram a teoria da sinalização, por meio das notícias transmitidas aos investidores referentes ao anúncio da distribuição de dividendos, de 1998 a 2006, para as ações integrantes do Ibovespa e observaram que os investidores reagiram ao receber as informações.

Ao analisar os fatores condicionantes da política de distribuição de dividendos das empresas do índice de dividendos da BM\&FBovespa, Fonteles et al. (2012) constataram que os sinais relativos à elevada política de distribuição de dividendos são afetados pela concentração de propriedade, rentabilidade, prosperidade e setor. Liu e Chen (2015) examinaram se os gestores alteram a política de dividendos para sinalizar a sua expectativa de lucros no mercado norte-americano. Os autores verificaram que a mudança visa sinalizar ganhos em escala de ativos, bem como evidências de mudanças prévias nos resultados e restauração de clientela de dividendos. Viana Júnior e Ponte (2015), por sua vez, investigaram a correlação entre distribuição de dividendos e fluxos de caixa futuros, em companhias listadas na BM\&FBovespa, entre 2007 e 2013. Os resultados sugeriram que a política de dividendos não explica o fluxo de caixa nas empresas.

Observa-se que existem evidências de que a política de dividendos pode atuar como um sinalizador de bem-estar econômico-financeiro da firma, o que reduz sua assimetria informacional e aumenta o seu valor (Loss e Sarlo Neto, 2003; Novis Neto e Saito, 2003). Além disso, a política de dividendos tem implicações na redução do problema de agência e na manutenção da reputação corporativa (Al-Kuwari, 2009; Zagonel, 2013). A referida teoria tem sido frequentemente utilizada em estudos sobre distribuição de lucro e reputação (Gillet et al., 2008).

$\mathrm{Na}$ percepção dos stakeholders, a repetição de comportamentos da firma traduz sua conduta e forma sua reputação, que pode ser favorável ou desfavorável, de modo a definir o seu comportamento futuro esperado pelos stakeholders (Thomaz e Brito, 2010). Gotsi e Wilson (2001) argumentam que a reputação corporativa compreende a avaliação geral dos stakeholders ao longo do tempo, baseada em experiências diretas do envolvido com a empresa e quaisquer outras formas de comunicação e simbolismo que fornecem informações sobre as suas ações. A reputação, nesse sentido, refere-se às impressões acumuladas de stakeholders internos e externos (Chun, 2005).

A reputação corporativa tem sido estudada por diversas áreas do conhecimento, como economia, estratégia, marketing, administração, contabilidade e sociologia (Fombrun e Van Riel, 1997). Esta pesquisa tem como objeto a reputação pela ótica da sociologia, que é construída a partir das avaliações do desempenho das empresas relativas às expectativas e normas, ou seja, construções sociais decorrentes dos rankings de reputação (Fombrun e Van Riel, 1997). 
Do exposto, para fins da presente pesquisa, a reputação corporativa, compreendida como um conjunto de percepções - positivas ou negativas- dos stakeholders sobre a empresa, é construída ao longo do tempo e depende do modo como as pessoas e empresas influenciam ou são influenciadas pelas ações da companhia (Barnett, Jermier e Lafertty, 2006; Roberts e Downling, 2002). Em outras palavras, a reputação corporativa pode ser constituída por um conjunto de atributos organizacionais, que se refletem na avaliação da conduta da empresa pelos stakeholders (Roberts e Dowling, 2002). Dessa forma, ao considerar um ambiente de assimetria informacional, a política de dividendos pode sinalizar para os stakeholders sobre a situação atual e perspectiva futura da empresa (Fairchild, 2010).

Ao considerar (a) que a reputação é como um elo entre as decisões de dividendos sequenciais, torna-se possível uniformizar custos de sinalização e obter um equilíbrio diferenciador (Gillet et al., 2008) e (b) que a política de distribuição de dividendos é uma forma de estabelecer a reputação da empresa, na medida que reduz a possibilidade de expropriação dos seus acionistas (La Porta et al., 2000) e emite sinais positivos para o mercado (Fonteles et al., 2012), apresenta-se a seguinte hipótese: a politica de dividendos, observada como um sinal de desempenho e redução de assimetria informacional, está associada com a reputação corporativa.

\section{Procedimentos metodológicos}

A população do estudo compreende as 100 empresas listadas no ranking "As empresas mais responsáveis e com melhor governança corporativa que atuam no Brasil", elaborado pela Merco, em 2014. Desenvolvido em parceria com o Instituto Brasileiro de Opinião Pública e Estatística (Ibope), o ranking analisa as opiniões de centenas de especialistas, empregados, diretores de empresas e jornalistas sobre os itens relativos ao comportamento ético da empresa, responsabilidade com funcionários, compromisso com meio ambiente e contribuição à comunidade.

Desse conjunto, foram excluídas 61 empresas, das quais 52 eram de capital fechado, oito por impossibilidade de acesso à distribuição de lucros e uma cujo exercício social não coincide com o ano civil. Desse modo, a amostra ficou definida em 39 companhias. Destaca-se que alguns estudos sobre reputação corporativa também apresentam limitação quanto a quantidade de observações, principalmente em razão a dificuldade para medir a reputação (Cardoso, De Luca, Lima e Vasconcelos, 2013; Fernández, Jara-Bertin e Pineaur, 2015).

Para o alcance dos objetivos, adotou-se a defasagem temporal para a variável lucro distribuído, em que a distribuição de lucro do exercício de 2013 relaciona-se com a criação de reputação corporativa do exercício posterior, 2014.

Os dados para a realização do estudo foram extraídos das Demonstrações Financeiras Padronizadas (DFPs) das empresas brasileiras -Balanço Patrimonial, Demonstração do Resultado do Exercício, Notas Explicativas e do Formulário de Referência, item 3.5-, referentes ao ano de 2013, disponíveis no website da BM\&FBovespa. A tabela 1 exibe as variáveis utilizadas na pesquisa. 
TABELA 1

Variáveis do estudo

\begin{tabular}{|c|c|c|}
\hline Variável & Operacionalização & Fundamentação \\
\hline $\begin{array}{l}\text { Reputação corporativa } \\
\text { (REP) }\end{array}$ & $\begin{array}{l}\text { Log da pontuação do ranking das empresas mais } \\
\text { responsáveis e com melhor govemança corporativa }\end{array}$ & $\begin{array}{l}\text { Cardoso et al. (2013); } \\
\text { Brammer, Millington e } \\
\text { Pavelin (2009). }\end{array}$ \\
\hline $\begin{array}{l}\text { Lucro distribuído } \\
\text { (DIS) }\end{array}$ & $\begin{array}{l}\text { Log do total distribuído com os acionistas } \\
\text { (dividendos e JSCP) }\end{array}$ & $\begin{array}{l}\text { Fonteneles et al. (2012); } \\
\text { Holanda e Coelho (2012); } \\
\text { Viana Júnior e Ponte } \\
(2015) \text {. }\end{array}$ \\
\hline Tamanho(TAM) & Logaritmo natural (Ln) do ativo & $\begin{array}{l}\text { Cardoso et al. (2013); } \\
\text { Fonteneles et al. (2012). }\end{array}$ \\
\hline $\begin{array}{l}\text { Endividamento } \\
\text { (END) }\end{array}$ & (Ativo - Patrimônio líquido)/ Ativo & $\begin{array}{l}\text { Bandeira, Góis, De Luca } \\
\text { e Vasconcelos (2015). }\end{array}$ \\
\hline Desempenho (DES) & EBITDA / Ativo & Bandeira et al. (2015). \\
\hline $\begin{array}{l}\text { Controle acionário } \\
(\mathrm{CON})\end{array}$ & $\begin{array}{l}\text { Variável dummy para controle familiar, estatal, } \\
\text { estrangeiro ou institucional, conforme a proporção } \\
\text { dos direitos de votos. }\end{array}$ & Fonteneles et al. (2012). \\
\hline Setor (SET) & $\begin{array}{l}\text { Cada setor econômico da BM\&FBovespa é } \\
\text { representado por uma dummy. }\end{array}$ & Fonteneles et al. (2012). \\
\hline
\end{tabular}

Fonte: elaborado pelos autores

Convém destacar o processo de normalização das variáveis reputação, lucro distribuído e tamanho, cuja decisão decorreu principalmente da observação da alta variabilidade dos dados observados. A literatura tem recorrido à normalização dos dados para fins de análise (Brammer et al., 2009; Fonteneles et al., 2012; Holanda e Coelho, 2012; Viana Júnior e Ponte, 2015).

Para a concretização do objetivo geral, foram aplicados o teste de correlação e a análise de correspondência, Anacor. Esta compreende uma técnica que expõe as associações entre um conjunto de variáveis categóricas (não métricas) organizadas em um mapa perceptual, o que permite uma análise visual da estrutura de dados (Fávero, Belfiore, Silva e Chan, 2009).

Fez-se, inicialmente, uma análise descritiva da política de distribuição de dividendos, exibindo-se sua representatividade por setor e por tipo de controle acionário. Realizou-se, posteriormente, a análise de homogeneidade (Homals), que consiste em uma análise de correspondência com múltiplos níveis e que faz uma análise à correlação entre todas as variáveis conjunta e simultânea (Fávero et al., 2009). Anteriormente à realização das respectivas análises, procedeu-se à realização do teste de Qui-quadrado $\left(\chi^{2}\right)$ a fim de identificar a significância das relações. 
Considerando que a Anacor e a Homals utilizam variáveis categóricas, as variáveis relativas à reputação corporativa e ao lucro distribuído foram agrupadas a partir da distribuição por meio de quartis, como mostra a tabela 2.

TABELA 2

Categorização das variáveis

\begin{tabular}{|c|c|c|c|}
\hline Nível & REP & Nível & DIST \\
\hline Baixo & Até 8.019 & Baixo & Até 11.918 \\
\hline Médio-baixo & 8.020 a 8.063 & Médio-baixo & 11.919 a 13.074 \\
\hline Médio-alto & 8.064 a 8.394 & Médio-alto & 13.075 a 14.183 \\
\hline Alto & Acima de 8.395 & Alto & Acima de 14.184 \\
\hline
\end{tabular}

Fonte: elaborado pelos autores

As categorias foram formadas com a finalidade de relacionar tais termos com o controle acionário e setor econômico, além de relacionar as variáveis reputação e distribuição de dividendos entre si.

\section{Análise e discussão dos resultados}

$\mathrm{Na}$ tabela 3, apresentam-se as pontuações médias da reputação das empresas, obtidas através do ranking, bem como as médias de lucro distribuído (dividendos e JSCP), por tipo de controle acionário.

TABELA 3

Reputação e distribuição de lucro por tipo de controle acionário

\begin{tabular}{lcccc}
\hline \multirow{2}{*}{ Controle } & \multicolumn{4}{c}{ Reputação corporativa } \\
\cline { 2 - 5 } & Baixa & Médio-baixa & Médio-alta & Alta \\
\hline Familiar & 3.013 & 3.086 & 3.482 & 8.428 \\
Institucional & 3.022 & 3.113 & 3.617 & 7.901 \\
Estrangeiro & 3.015 & 3.104 & 3.785 & 5.186 \\
Estatal & - & 3.041 & 3.282 & 5.734 \\
\hline \multirow{2}{*}{ Controle } & \multicolumn{4}{c}{ Lucro distribuído (em RS mil) } \\
& Baixa & Médio-baixo & Médio-alto & Alta \\
\hline Familiar & 91.784 & 315.836 & 880.137 & - \\
Institucional & 51.600 & 301.567 & 827.435 & 6.164 .303 \\
Estrangeiro & 144.252 & 204.587 & 1.100 .473 & 3.376 .144 \\
Estatal & - & - & 537.465 & 5.760 .206 \\
\hline
\end{tabular}

Fonte: dados da pesquisa

Constata-se que as empresas com baixa reputação estão sob controle familiar, institucional ou estrangeiro, não sendo constatada nenhuma sob controle do Estado. Nota-se uma singela diferença de reputação entre 
as categorias baixa, médio-baixa e médio-alta, que se mostra mais representativa quando comparada com as empresas de alta reputação.

Observa-se que as empresas familiares apresentam nível de reputação mais elevada. Caracteriza-se a reputação sob a ótica sociológica, segundo Fombrun e Van Riel (1997), na qual a Natura Cosméticos S.A. é a empresa com maior pontuação de reputação. Com relação ao valor médio de lucro distribuído, não foram encontradas empresas familiares com alta distribuição de lucro. As empresas com a média mais alta de lucro distribuído pagaram uma média de $\mathrm{R} \$ 880$ milhões em forma de dividendos e JSCP aos seus acionistas em 2013.

Nota-se, ainda, que as empresas estatais são aquelas com maiores distribuições de lucro, as quais registram uma média de R \$ 5,8 bilhões, sem ter empresas com baixa ou médio-baixa distribuição. Assim, deve acentuarse que, no grupo analisado, não há empresa estatal com baixa reputação nem baixa distribuição de lucro. Percebe-se que as empresas com melhores distribuições de lucro são aquelas sob controle institucional. De fato, a empresa com a maior distribuição de lucro em 2013 dessa categoria foi a Vale S.A, com um total aproximado de $\mathrm{R} \$ 9,3$ bilhões.

A tabela 4 mostra as médias de pontuação da reputação das empresas, obtida por meio do ranking, bem como as médias de lucro distribuído, segregadas por setor. Entre as empresas com baixa reputação, destacamse todas as de tecnologia da informação, o que suporta, em parte, os achados de Bandeira et al. (2015), os quais observaram que nesse segmento há predominância de alta reputação negativa. Apenas uma empresa de petróleo, gás e biocombustíveis detém alta reputação corporativa. 
TABELA 4

Reputação e distribuição de lucro por setor econômico

\begin{tabular}{|c|c|c|c|c|}
\hline \multirow{2}{*}{ Setor } & \multicolumn{4}{|c|}{ Reputação corporativa } \\
\hline & Baixa & Médio-baixa & Médio-alta & Alta \\
\hline UT & - & 3.041 & 3.451 & - \\
\hline $\mathrm{CC}$ & 3.004 & 3.103 & 3.975 & - \\
\hline $\mathrm{CNC}$ & 3.021 & 3.131 & 3.944 & 7.016 \\
\hline PGB & - & - & - & 7.047 \\
\hline MB & 3.008 & 3.048 & 3.184 & 7.281 \\
\hline $\mathrm{CT}$ & 3.030 & 3.046 & - & - \\
\hline BI & - & 3.123 & 3.288 & 4.509 \\
\hline $\mathrm{TC}$ & - & 3.064 & 3.572 & - \\
\hline TI & 3.040 & - & - & - \\
\hline $\mathrm{F}$ & 3.006 & 3.132 & 3.998 & 6.806 \\
\hline \multirow{2}{*}{ Setor } & \multicolumn{4}{|c|}{ Lucro distribuído (R\$ mil) } \\
\hline & Baixo & Médio-baixo & Médio-alto & Alto \\
\hline UT & - & - & 734.158 & 1.655 .594 \\
\hline $\mathrm{CC}$ & 94.814 & 183.079 & - & - \\
\hline $\mathrm{CNC}$ & 115.966 & 235.054 & 792.623 & 3.822 .216 \\
\hline PGB & - & - & - & 9.301 .024 \\
\hline MB & - & 338.140 & 800.000 & 9.319 .000 \\
\hline $\mathrm{CT}$ & 21.267 & - & 1.301 .374 & - \\
\hline BI & 103.196 & 332.055 & - & - \\
\hline $\mathrm{TC}$ & - & - & 756.472 & 2.484 .000 \\
\hline TI & - & 155.759 & - & - \\
\hline $\mathrm{F}$ & 103.556 & - & 960.852 & 5.165 .969 \\
\hline
\end{tabular}

Fonte: dados da pesquisa

Legenda: utilidade pública (UT), consumo cíclico (CC), consumo não cíclico (CNC), petróleo, gás e bicombustíveis (PGB), materiais básicos $(\mathrm{MB})$, construção e transporte $(\mathrm{CT})$, bens

industriais (BI), telecomunicações (TC), tecnologia da informação (TI), financeiros e outros (F).

Quanto à média de distribuição de lucro, verificou-se que as empresas com maiores volumes pertencem aos setores materiais básicos e petróleo, gás e biocombustíveis, com aproximadamente $\mathrm{R} \$ 9,3$ bilhões. Ressaltase ainda que apenas o setor consumo não cíclico possui empresas nas quatro categorias de reputação e distribuição de lucro, conforme mostra a tabela 4.

A tabela 5 apresenta os valores correspondentes à estatística descritiva dos dados. Observa-se que todas as variáveis apresentaram baixa heterogeneidade dos dados, com exceção da margem EBITDA. A política de dividendos ( $\log$ do lucro distribuído) registrou coeficiente de variação $11,84 \%$, o que sugere que o lucro distribuído se comporta de forma homogênea entre as empresas. 
TABELA 5

Estatística descritiva das variáveis

\begin{tabular}{ccccc}
\hline Variável & Mínimo & Máximo & Média & DP \\
\hline REP & 8,01 & 9,21 & 8,26 & 0,35 \\
DIS & 9,96 & 16,05 & 13,11 & 1,55 \\
TAM & 14,08 & 20,87 & 17,01 & 1,81 \\
END & 0,30 & 0,93 & 0,63 & 0,17 \\
DES & 0,01 & 0,41 & 0,14 & 0,09 \\
\hline
\end{tabular}

Fonte: dados da pesquisa

Legenda: reputação corporativa (REP), lucro distribuído (DIS), tamanho da empresa (TAM), endividamento da firma (END), desempenho empresarial (DES).

Posteriormente, procurou-se analisar as respectivas políticas de dividendos em termos de distribuição do lucro. Dentre as 39 empresas da amostra, uma proporção mínima de distribuição do lucro apresenta variações. Entretanto, a maioria das empresas, $72 \%$, adotam a proporção mínima de $25 \%$ do lucro líquido ajustado (LLA), conforme instrução da Lei n 6404/1976, na forma de mínimo obrigatório. Enquanto que as demais adotam proporções inferiores a $25 \%$ e entre $30 \%$ e $50 \%$ do LLA. Tais achados corroboram o estudo de Vancin e Procianoy (2014), que verificaram a adoção de 25\% do LLA pelas empresas brasileiras.

Constatou-se, também, que a distribuição do lucro se deu sob as formas de dividendos ( 12 empresas) e JSCP ( 3 empresas), além de que 24 empresas distribuíram o lucro de ambas as formas. Por outro lado, Loss e Sarlo Neto (2003) apontam que, entre 1997 e 2001, houve maior distribuição de lucro sob a forma de dividendos; observou-se, no entanto, uma tendência decrescente à adoção do JSCP.

Do total de R \$ 58,3 bilhões distribuídos pelas empresas, $38 \%$ se deram sob a forma de dividendos e $62 \%$ sob a forma de JSCP. O maior valor pago sob a forma de JSCP pode ser explicado, segundo Sousa Neto, Jordão, Pinheiro e Marquezine (2014), pelos benefícios fiscais advindos da adoção dessa política, ou seja, através de uma economia tributária.

Quanto à remuneração dos acionistas, 69\% das companhias pagam, na forma de dividendos e/ou JSCP, acima do mínimo obrigatório, o que corrobora o que Fonteles et al. (2012) e Vancin e Procianoy (2014) afirmam. Posteriormente, a tabela 6 apresenta a periodicidade da distribuição do lucro nas empresas.

TABELA 6

Periodicidade de distribuição do lucro

\begin{tabular}{lrrrrrrrr}
\hline Periodicidade & $\mathbf{N}$ & $\mathbf{( \% )}$ & Dividendos & $\mathbf{( \% )}$ & JSCP & $\mathbf{( \% )}$ & Total & $\mathbf{( \% )}$ \\
\hline Anual & 13 & 33,33 & $1.487 .763,46$ & 16,11 & $967.166,31$ & 13,67 & $2.454 .929,77$ & 15,05 \\
Semestral & 13 & 33,33 & $136.920,80$ & 1,48 & $815.130,77$ & 11,52 & $952.051,57$ & 5,84 \\
Quadrimestral & 01 & 2,56 & $315.082,00$ & 3,41 & 0,00 & 0,00 & $315.082,00$ & 1,93 \\
Trimestral & 07 & 17,95 & $1.298 .866,29$ & 14,06 & $576.578,29$ & 8,15 & $1.875 .444,58$ & 11,50 \\
Mensal & 01 & 2,56 & $4.077 .908,00$ & 44,15 & $3.224 .050,00$ & 45,56 & $7.301 .958,00$ & 44,76 \\
Não divulgado & 04 & 10,26 & $1.920 .799,75$ & 20,79 & $1.493 .500,00$ & 21,11 & $3.414 .299,75$ & 20,93 \\
\hline Total & $\mathbf{3 9}$ & $\mathbf{1 0 0 , 0 0}$ & $\mathbf{9 . 2 3 7 . 3 4 0 , 3 0}$ & $\mathbf{1 0 0 , 0 0}$ & $\mathbf{7 . 0 7 6 . 4 2 5 , 3 7}$ & $\mathbf{1 0 0 , 0 0}$ & $\mathbf{1 6 . 3 1 3 . 7 6 5 , 6 7}$ & $\mathbf{1 0 0 , 0 0}$
\end{tabular}


Nota-se que 26 empresas, $66,66 \%$ da amostra, apresentam distribuição semestral ou anual, confirmando os resultados de Fonteles et al. (2012), que indicam a predominância da distribuição anual, seguida da semestral. Ressalta-se que poucas empresas distribuem lucro mensalmente, o que indica que essa prática ainda é pouco usual no mercado brasileiro.

Ademais, os resultados mostram que as empresas da amostra distribuem maiores valores através da distribuição de dividendos, contudo com uma diferença pequena em relação aos JSCP, de 2,2 milhões de reais. Do total de lucro distribuído pelas empresas, a maior representação tem periodicidade mensal. Ao longo do ano, a empresa Bradesco S.A. distribuiu, mensalmente, 44,76\% do lucro. Ressalta-se que parte representativa das empresas que realizam distribuições anuais e semestrais, distribuíram cerca de $21 \%$ do total distribuído pelas empresas da amostra, com valor monetário de aproximadamente 3,4 milhões de reais.

Posteriormente, à análise descritiva dos dados partiu-se para a análise de associação. A Figura 1 exibe um mapa perceptual resultante da aplicação da análise de Homals.

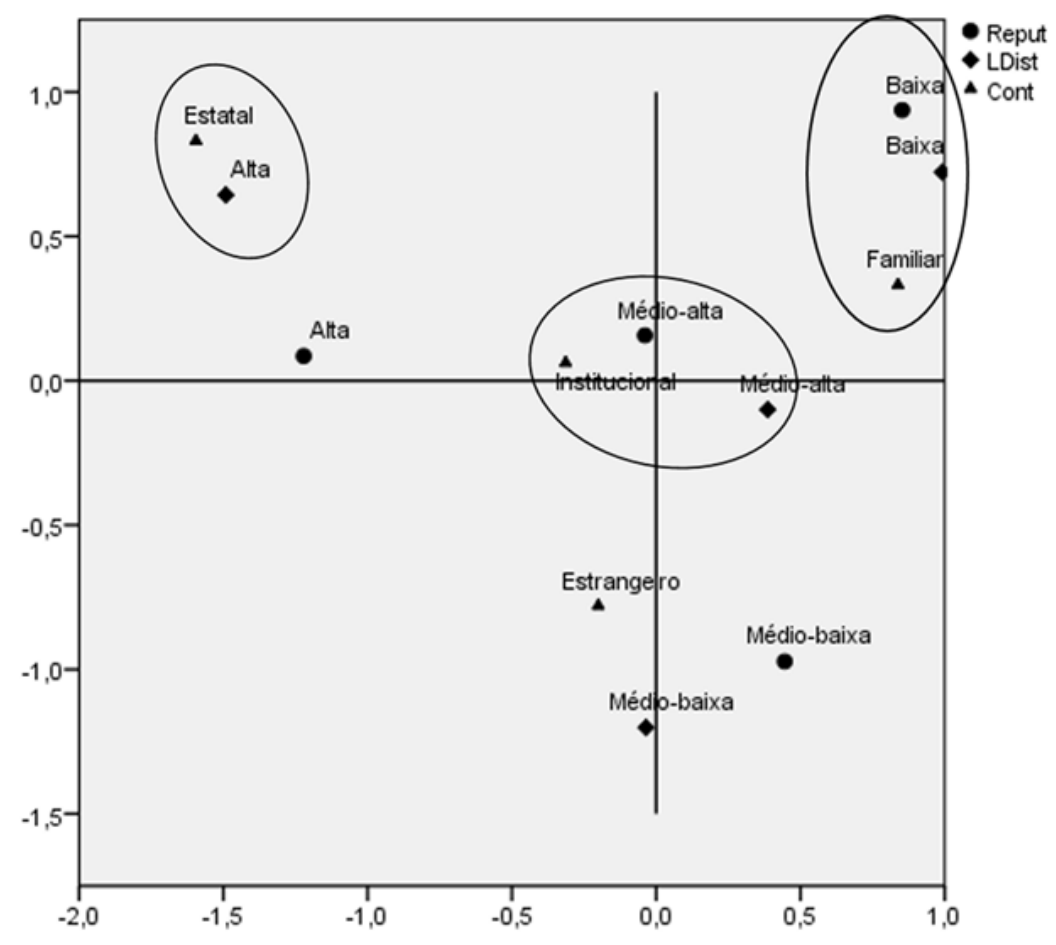

FIGURA 1

Política de dividendos, reputação e controle acionário Fonte: dados da pesquisa

Observa-se, na figura 1, uma associação de homogeneidade entre empresas estatais e alta distribuição de lucro. Tais resultados guardam consonância com os achados de Al-Kuwari (2009), segundo o qual as empresas não financeiras, de mercados emergentes, controladas pelo governo, distribuem mais dividendos.

Observa-se, ainda, uma associação de homogeneidade entre baixa distribuição de lucro, baixa reputação e controle familiar. He, Li e Tang (2012) verificaram que as empresas familiares distribuem menos dividendos do que as estatais e as não familiares. Assim, pode-se dizer que a baixa distribuição por empresas familiares é um sinal captado pelo mercado como negativo, o que consequentemente faz que a reputação dessas empresas seja mais baixa. Nota-se, ainda, que as empresas sob controle institucional estão associadas a uma reputação médio-alta, o que sugere que os acionistas as percebem como atraentes. 
A figura 2 apresenta o mapa perceptual da análise de Homals entre política de dividendos, reputação e setor. Verifica-se que a distribuição de lucros das empresas de telecomunicações se apresentam como médio-alta, ao passo que as de consumo cíclico estão associadas a uma baixa distribuição de lucro.

Destaca-se que as empresas de telecomunicações estão sob controle estrangeiro, o que pode explicar tal distribuição, haja vista que a alta distribuição de lucro pode ser um atrativo para investidores estrangeiros. Já as empresas de consumo cíclico podem ser mais afetadas por sazonalidades, razão pela qual seus resultados registram maiores oscilações.

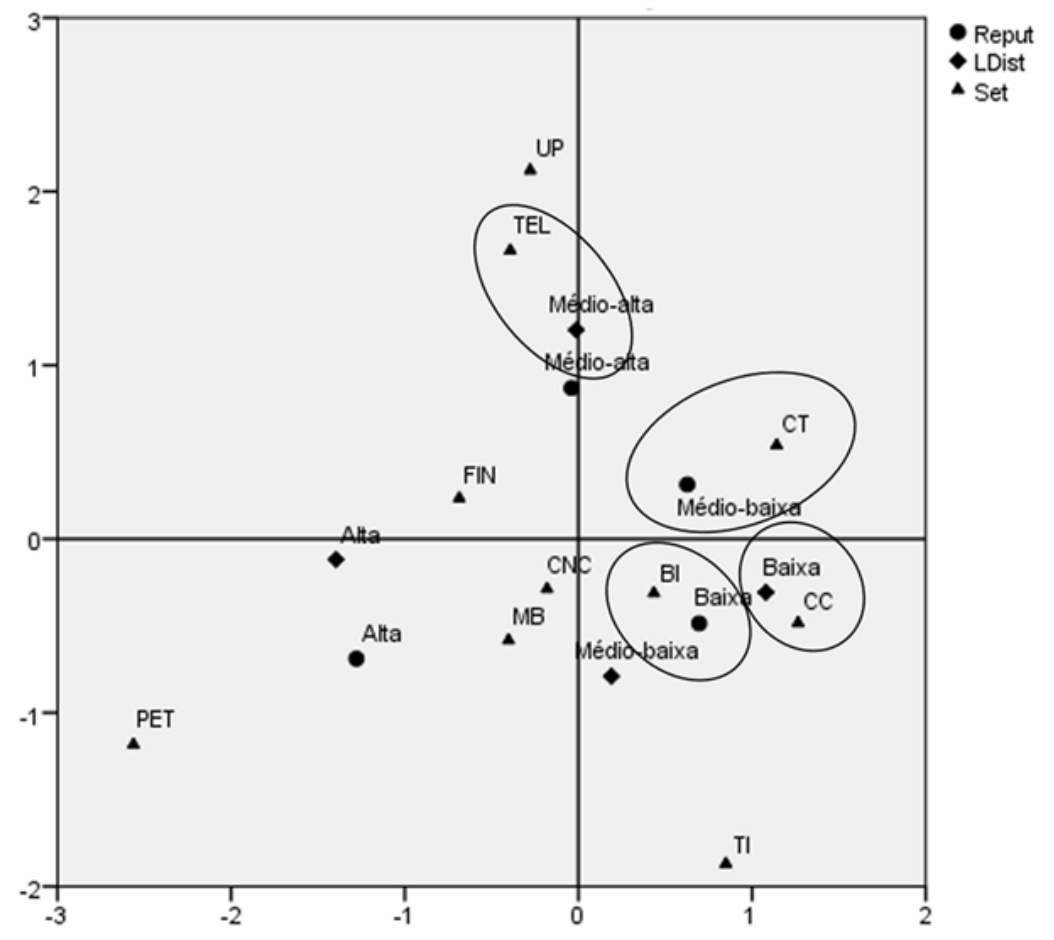

FIGURA 2

Política de dividendos, reputação e setor

Fonte: dados da pesquisa

Observa-se, ainda, na figura 2, que as empresas de construção e transporte estão associadas a médioalta reputação, enquanto as de bens industriais relacionam-se a baixa reputação. Tais achados contrastam, parcialmente, com os de Bandeira et al. (2015), ao indicar que o setor de bens industriais apresenta baixo nível de reputação negativo, enquanto as empresas de construção e transporte associam-se a médios níveis de reputação negativos.

Em atendimento ao objetivo do estudo, a tabela 7 apresenta os resultados da Correlação de Spearman. Observa-se uma correlação positiva entre política de dividendos e reputação, o que corrobora os resultados de Gillet, Lapointe e Raimbourg (2008). Infere-se, nesse sentido, que as empresas com níveis mais altos de distribuição de lucros, por meio de dividendos e/ou JSCP, emitem melhores sinais para os shareholders, e assim, podem elevar seus níveis de reputação. 
TABELA 7

Matriz de Correlação

\begin{tabular}{llllll}
\hline Variável & \multicolumn{1}{c}{ LDIST } & \multicolumn{1}{c}{ LREP } & TAM & END & MEBT \\
\hline DIST & 1,00 & & & & \\
REP & $0,54^{* * *}$ & 1,00 & & & \\
TAM & $0,77^{* * *}$ & $0,56^{* * *}$ & 1,00 & & \\
END & 0,08 & 0,14 & 0,26 & 1,00 & \\
DES & $-0,05$ & $-0,28^{*}$ & $-0,55^{* * *}$ & $-0,44^{* * *}$ & 1,00 \\
\hline
\end{tabular}

Os resultados apresentados, à luz da teoria da sinalização, apontam a distribuição de lucro como um sinal que, juntamente com a adoção de mecanismos de governança, podem reduzir a assimetria da informação e manter a reputação da empresa, o que ratifica os achados de Al-Kuwari (2009), e Novis Neto e Saito (2003). Por conseguinte, os resultados sugerem que a política de dividendos adotada pela empresa detém um conteúdo informacional, que emite sinais para os investidores, os quais, a partir dessas percepçóes, constroem a reputação corporativa.

Ademais, verifica-se que as empresas grandes distribuem maiores lucros e apresentam níveis de reputação mais altos, o que confirma os achados de Fonteles et al. (2012), e Holanda e Coelho (2012). Noutro turno, na medida em que aumenta o tamanho da empresa, seu desempenho reage reduzindo-se, o que confirma o afirmado por Roberts e Dowling (2002), segundo os quais as maiores empresas estão correlacionadas com um menor desempenho. Esse resultado pode estar relacionado com o ciclo de vida da firma, o que pode indicar a realização de reinvestimento, em empresas maduras ou em empresas na fase de declínio (Dickinson, 2011).

Realizou-se também a análise de correspondência (Anacor) para se examinar a associação entre os níveis de reputação e de distribuição de lucro. Ante sua realização, procedeu-se ao teste Qui-quadrado $\left(\chi^{2}\right)$, o qual apontou a presença de significância, ao nível de $5 \%$. Assim, rejeitou-se a hipótese de que não há associação entre as variáveis. A figura 3 exibe o mapa perceptual, a partir do qual podem ser analisados os resultados. 


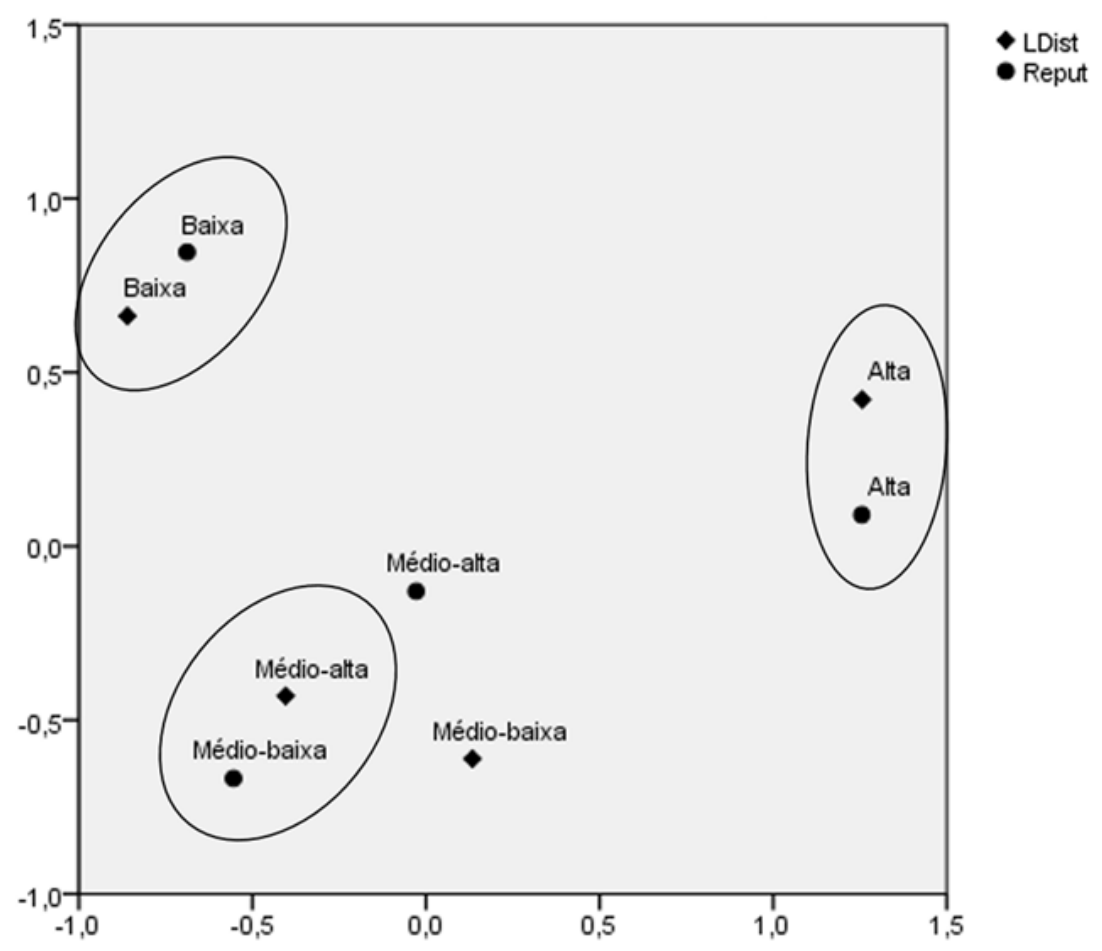

FIGURA 3

Associação entre política de dividendos e reputação

Fonte: dados da pesquisa

Os achados revelam que há associação entre os níveis mais altos de reputação e a distribuição de dividendos e que se mostram semelhantes para o nível mais baixo, confirmando-se, assim, os resultados inferidos da Anacor de que uma boa reputação está correlacionada com uma boa política de dividendos. Ao considerar que as empresas da amostra com melhor reputação também são aquelas com melhores índices de responsabilidade e governança corporativa, este estudo corrobora o argumento de Zagonel (2013), segundo o qual as empresas com melhores indicadores de governança tendem a distribuir mais lucro.

\section{Conclusões}

A pesquisa investigou a associação entre política de dividendos e reputação corporativa nas empresas mais responsáveis e com melhor governança corporativa. Para tanto, de início, realizou-se a análise acerca da política de dividendos adotada por 39 empresas em 2013 . Observou-se que $72 \%$ das empresas adotam como mínimo obrigatório a distribuição de $25 \%$ do lucro líquido ajustado, enquanto que cerca de $69 \%$ distribuem lucro acima do mínimo obrigatório, sob a forma de dividendos e/ou JSCP. Destaca-se a elevada participação de JSCP como forma de distribuição.

Averiguou-se que as empresas brasileiras mais responsáveis e com melhor governança dão preferência à distribuição de lucro sob a forma de JSCP, o que encontra apoio na teoria da preferência tributária proposta por Damodaran (2004); haja vista que a adoção dessa política acarreta benefícios fiscais tanto para a empresa como para o investidor. Notou-se que as empresas familiares estão associadas a baixa reputação, o que sugere que apresentam conflitos de agência, principalmente entre acionistas majoritários e minoritários, o que pode resultar na expropriação dos minoritários e, consequentemente, na diminuição da reputação. Destarte, tais 
empresas também apresentam baixa distribuição de lucro, o que pode ser explicado pelo fato de esse grupo ter maior interesse em retorno de longo prazo, já que a propriedade tende a permanecer sob controle da família.

Constatou-se que os setores de telecomunicações, bens industriais, consumo cíclico e construção e transporte estão associados a um nível específico de reputação e/ou distribuição de lucro. Tais achados sugerem que o setor pode ser uma variável capaz de interferir na correlação entre a política de dividendos adotada por uma empresa e a forma como os shareholders a percebem.

Os achados do estudo permitem afirmar que há uma correlação positiva entre a política de dividendos e a reputação corporativa, de modo que uma alta reputação está associada a uma alta distribuição de lucro, bem como uma baixa reputação é associada a uma baixa distribuição. Confirma-se, assim, a hipótese da pesquisa: a política de dividendos da empresa, observada como um sinal de rentabilidade e redução de assimetria informacional, está correlacionada com a reputação corporativa.

Conclui-se que, em um ambiente de assimetria de informações, os investidores percebem os sinais emitidos pela empresa de modo que constroem a sua reputação, conforme preconiza a teoria da sinalização. Dessa forma, afirma-se que a política de dividendos adotada pela empresa detém um conteúdo informacional, que emite sinais para o mercado, principalmente para os shareholders, e que são percebidos pelos investidores, os quais, a partir dessas percepções, constroem a reputação da empresa. Por conseguinte, as empresas que distribuem baixos lucros emitem sinais pouco positivos e, consequentemente, detêm menor reputação.

Para a teoria da sinalização, o estudo pode fortalecer a existência de correlação entre reputação e política de dividendos, haja vista que se considera que a política de dividendos carrega conteúdo informacional, de modo que emite sinais aos stakeholders, que, por sua vez, implicam a construção da reputação da empresa. Em termos práticos, o estudo pode revelar que, de fato, a política de dividendos da empresa implica relação construtiva da reputação corporativa, elemento importante para a manutenção da competitividade da firma.

O estudo apresenta limitações quanto aos aspectos temporais e suas inferências representam uma amostra pequena para uma conclusão definitiva. Portanto, sugere-se a análise longitudinal, com o intuito de observar possíveis anomalias relacionais entre os construtos da pesquisa. Recomenda-se, também, a utilização de ferramentas estatísticas robustas de influência e comportamento da relação, bem como considerar o uso de variáveis adicionais, como, por exemplo, a concentração acionária, a oportunidade de crescimento, o marketto-book e o risco, que podem interferir na correlação entre reputação corporativa e política de dividendos.

\section{Agradecimentos}

O artigo é produto de uma investigação científica relacionada ao projeto Reputação corporativa: constructos e implicaçóes para a criação de valor, cadastrado no Conselho Nacional de Desenvolvimento Científico e Tecnológico (CNPq).

\section{Referências}

Al-Kuwari, D. (2009). Determinants of the dividend policy in emerging stock exchanges. Global Economy \& Finance Journal, 2(2), 38-63.

Almeida, L. A. G., Tavares, F. O. e Pereira, E. T. (2014). Determinantes da política de dividendos em Portugal. Revista Universo Contábil, 10(4), 162-181.

Assaf Neto, A., Ambrozini, M. A. e Lima, F. G. (2007). Dividendos: teoria e prática. Ribeirão Preto: Inside Books.

Bandeira, M. T. S. S., Góis, A. D., De Luca, M. M. M. e Vasconcelos, A. C. (2015). Reputação corporativa negativa e o desempenho empresarial. Revista de Contabilidade e Organizações, 9(24), 71-83.

Barnett, M. L., Jermier, J. M. e Lafferty, B. A. (2006). Corporate reputation: The definitional landscape. Corporate Reputation Review, 9(1), 26-38. 
Brammer, S., Millington, A. e Pavelin, S. (2009). Corporate reputation and women on the board. British Journal of Management, 20(1), 17-29.

Cardoso, V. I. C., De Luca, M. M. M., Lima, G. A. S. F. L. e Vasconcelos, A. C. (2013). Reputação corporativa nas empresas brasileiras: uma questão relevante para o desempenho empresarial? Revista Contemporânea de Contabilidade, 10(21), 115-136.

Chun, R. (2005). Corporate reputation: Meaning and measurement. International Journal of Management Reviews, 7(2), 91-109.

Damodaran, A. (2004). Finanças corporativas: teoria e prática. Porto Alegre: Bookman.

Dami, A. B. T., Rogers, P. e Ribeiro, K. C. S. (2007). Estrutura de propriedade no Brasil: evidências empíricas do grau de concentração acionária. Revista Contemporânea de Economia e Gestão, 5(2), 21-30.

Dickinson, V. (2011). Cash flow patterns as a proxy for firm life cycle. The Accounting Review, 86(6), 1969-1994.

Fairchild, R. (2010). Dividend policy, signalling and free cash flow: An integrated approach. Managerial Finance, 36(5), 394-413.

Fairchild, R., Guney, Y. e Thanatawee, Y. (2014). Corporate dividend policy in Thailand: theory and evidence. International Review of Financial Analysis, 31, 129-151.

Fávero, L. P., Belfiore, P., Silva, F. L. e Chan, B. L. Análise de dados: modelagem multivariada para tomada de deciões. Rio de Janeiro: Elsevier.

Fernández, L. V., Jara-Bertin, M. e Pineaur, F. V. (2015). Prácticas de responsabilidad social, reputación corporativa y desempeño financiero. Revista de Administração de Empresas, 55(3), 329-344.

Fombrun, C. e Van Riel, C. B. M. (1997). The reputational landscape. Corporate Reputation Review, 1(1/2), 5-13.

Fonteles, I. V., Peixoto Júnior, C. A., Vasconcelos, A. C. e De Luca, M. M. M. (2012). Política de dividendos das empresas participantes do Índice Dividendos da BM\&FBovespa. Contabilidade Vista e Revista, 23(3), 173-204.

Gillet, R., Lapointe, M. e Raimbourg, P. (2008). Dividend policy and reputation. Journal of Business, Finance and Accounting, 35(3/4), 516-540.

Gonzáles, P. G. (1998). As mudanças nas políticas de dividendos e o mercado financeiro. Caderno de Estudos, 10(19), $1-12$.

Gotsi, M. e Wilson, A. M. (2001). Corporate reputation: Seeking a definition. Corporate Communications, 6(1), 24-30.

He, T. T., Li, W. X. B. e Tang, G. Y. N. (2012) Dividends behavior in state - versus family - controlled firms: Evidence from Hong Kong. Journal Business Ethics, 110(1), 97-112.

Holanda, A. P. e Coelho, A. C. D. (2012). Dividendos e efeito clientela: evidências no mercado brasileiro. Revista de Administração de Empresas, 52(4), 448-463.

Jensen, M. C. e Meckling, W. H. (1976). Theory of the firm: Managerial behavior, agency costs and capital structures. Journal of Financial Economics, 3(4), 305-360.

La Porta, R., Lopez-de-Silanez, F., Shleifer, L. e Vishny, R. W. (2000). Agency problems and dividend policies around the world. The Journal of Finance, 55(1), 1-33.

Lei 6404 de 1976, Dispõe sobre as Sociedades por Ações, Presidência da República $§$ Presidência da República, Planalto, Brasília, 15 de dezembro de 1976.

Lei 9249 de 1995, Altera a legislação do imposto de renda das pessoas jurídicas, bem como da contribuição social sobre o lucro líquido, e dá outras providências, Presidência da República § Presidência da República, Planalto, Brasília, 26 de dezembro de 1995.

Liu, C. e Chen, A. (2015). Do firms use dividend changes to signal future profitability? A simultaneous equation analysis. International Review of Financial Analysis, 37, 194-207.

Loss, L. e Sarlo Neto, A. (2003). Política de dividendos, na prática, é importante? Revista Contabilidade \& Finanças, 14(ed. com.), 39-53.

Moreiras, L. M. F., Tambosi Filho, E. e Garcia, F. G. (2012). Dividendos e informação assimétrica: análise do novo mercado. Revista de Administração da USP, 47(4), 671-682. 
Novis Neto, J. A. e Saito, R. (2003). Pagamentos de dividendos e persistência de retornos anormais das ações: evidência do mercado brasileiro. Revista de Administração da USP, 38(2), 135-143.

Pietro Neto, J., Decourt, R. F. e Galli, O. C. (2011). Proventos - A teoria da sinalização: variações de mercado. Revista de Administração FACES Journal, 10(4), 150-168.

Roberts, P. W. e Dowling, G. R. (2002). Corporate reputation and sustained superior financial performance. Strategic Management Journal, 23(12), 1077-1093.

Ross, S. A., Westerfield, R. W. e Jaffe, J. F. (2013). Corporate finance. 10th ed. New York: McGraw-Hill.

Salsa, M. L. C. R. (2010). Política de dividendos e ciclo de vida das empresas. Revista Encontros Cientificos - Tourism \& Management Studies, (6), 162-174.

Shleifer, A. e Vishny, R. (1997). A survey of corporate governance. Journal of Finance, 52(2), 737-775

Sousa Neto, J. A., Jordão, R. V. D., Pinheiro, J. L. e Marquezine, R. P. (2014). Juros sobre capital próprio como forma de remuneração de acionistas: um estudo sobre o conflito de agência e as práticas de planejamento tributário. Revista de Administração FACES, 13(4), 90-108.

Spence, M. (1973). Job market signaling. The Quartely Journal of Economics, 87(3), 355-374.

Thomaz, J. C. e Brito, E. P.Z. (2010). Reputação corporativa: construtos formativos e implicações para a gestão. Revista de Administração Contemporânea, 14(2), 229-250.

Vancin, D. F. e Procianoy, J. L. (2014, setembro). Os fatores determinantes do pagamento de dividendos: um approach inovador. Anais do Encontro Nacional da Associação Nacional de Pós-Graduação e Pesquisa em Administração, Rio de Janeiro, RJ, Brasil, 38. Recuperado de http://www.anpad.org.br/admin/pdf/2014_EnANPAD_FIN18 20.pdf

Viana Júnior, D. B. C. e Ponte, V. M. R. (2015). Política de dividendos e fluxos de caixa: um estudo à luz da teoria da sinalização. Revista Ciências Administrativas, 21(1), 211-236.

Zagonel, T. (2013). Política de dividendos, tributação e governança corporativa no Brasil (Dissertação de mestrado em PPGA/UFRGS), Universidade Federal do Rio Grande do Sul, Porto Alegre.

\section{Notas}

* Artigo de investigação científica.

\section{Licencia Creative Commons CC BY 4.0}

Para citar este artigo: Sousa da Silva, E. M., Carvalho de Vasconcelos, A., Nobre Parente, P. H. e Mendes De Luca, M. M. (2017). Política de dividendos e reputação nas empresas mais responsáveis e com melhor governança corporativa. Cuadernos de Contabilidad, 18(46). 1-17. https://doi.org/10.11144/Javeriana. cc18-46. pdre 